\title{
Preclinical evaluation of a novel non-steroidal glucocorticoid receptor agonist with low systemic exposure and reduced potential for skin atrophy
}

H. Norsgaard ${ }^{1}$, M. Stahlhut ${ }^{1}$, S. Eirefelt, N. Svitacheva, P. S. Johnson, M. Krogh-Madsen, T. Marstrand, D. A. Ewald, K. N. Dack and A. Ollerstam. LEO Pharma, Ballerup, Denmark

${ }^{1}$ Joint first authors

\section{ABSTRACT}

With the aim to provide an effective and safe topical treatment of skin inflammation, we here describe a novel non-steroidal glucocorticoid receptor (GR) agonist, LEO 134310, with low systemic exposure and reduced potential for skin atrophy induction.

The most well-described anti-inflammatory activity of GR agonists is the inhibition of transcriptional activation of pro-inflammatory genes by NF-KB and AP-1. Further, a number of genes (e.g., FKBP5, GILZ) is induced by activated $G R$.

Major systemic adverse effects of GR activation relate to suppression of the hypothalamic-pituitary-adrenal (HPA) axis, whereas the main local adverse effect is skin atrophy. The structurally related mineralocorticoid receptor (MR) can be activated by steroidal GR agonists, and MR activation has been suggested to cause, at least partially, skin atrophy.

With glucocorticoids adverse events are often observed and can limit the duration of treatment. Our data indicate that the non-steroidal GR agonist LEO 134310 retains anti-inflammatory activity, while it may offer improved safety for topical treatment of skin diseases such as atopic dermatitis and psoriasis.

\section{MATERIALS AND METHODS}

GR binding assay - Binding of GR agonists to human GR was evaluated in a fluorescence polarization assay to compete $2.5 \mathrm{nM}$ Fluormone ${ }^{\mathrm{TM}} \mathrm{GS1}$ (Thermo Fisher)

TNFalpha inhibition assays -PBMCs were from human buffy coats or animal whole blood

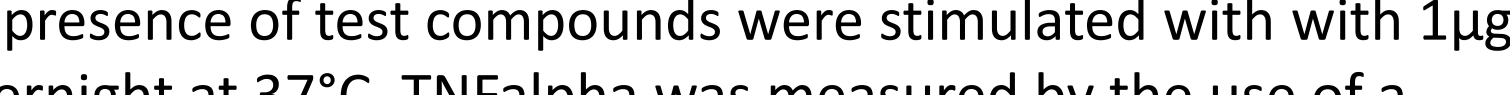
commercial AlphaLISA (Perkin Elmer).

MR agonist assay - This study was performed at Indigo Biosciences, PA, using their roprietary luciferase reporter cells expressing the native MR receptor. Luminescence was

Selectivity screening on nuclear receptors - Studies were performed at CEREP, France, using

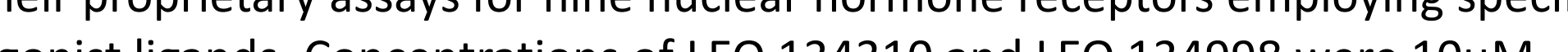

In vivo studies - Animal experimental procedures as well as animal housing and husbandry were in compliance with Danish and EU legislation.

PA induced skin inflammation in mice - Skin inflammation on female BALB/c mice (Taconic $M \& B, D K$ ) was induced by repeated topical application of TPA in acetone on the inner and outer surface of the ear on study days $1,3,5,8$ and 10 . Treatments were applied twice dally on days $8,9,10$, and once on day 11 in a volume of $10 \mu$ each on inner and outer ear

Local tolerance study in minipigs - Five male Göttingen SPF mini-pigs (Ellegaard Göttingen Minipigs A/S, Dalmose, DK) were treated for 28 days 6 hours daily with $25 \mu \mathrm{L}$ of either topical formulation on an area of $2.5 \mathrm{~cm} \times 2.5 \mathrm{~cm}$ : LEO vehicle (transcutol:acetone (1:9) with $10 \%$ hydroxypropylcellulose), Clobetasol proprionate $0.05 \%$ Clinical formulation; CP $0.05 \%$ in LEO vehicle. $L E O 1343102 \%$ in $L E O$ vehicle. One test field in each animal was remained untreated. Skin reactions at the application sites were observed daily prior to dosing and the day of necropsy. Skin biopsies were taken from anaesthetized animals 24 hours after the last treatment.

Human skin explants - The human full-thickness NativeSkin model (NS002; GenoSkin, France) was used. Test compounds were applied in duplicates or triplicates on the skin was performed using the following Taaman ${ }^{\circ}$ gene expression assays (FKBP5Hs01561006_m1, TSC22D3 (GILZ)-Hs00608272_m1, ACTB-Hs99999903 m1, PPIAHs99999904_m1, GAPDH-Hs99999905_m1). A geometric mean of the reference genes ACTB, PPIA and GAPDH was used for normalization.

\section{ABBREVIATIONS}

$\begin{array}{ll}\text { LEO 134310 } & \text { non-steroidal GR agonist } \\ \text { LEO 134998 } & \text { metabolite of LEO 134310 } \\ C P & \text { clobetasol propionate } \\ B M V & \text { betamethasone valerate } \\ T P A & \text { phorbol ester } \\ G R & \text { glucocorticoid receptor } \\ M R & \text { mineralocorticoid receptor } \\ P B M C & \text { peripheral blood mononuclear cells } \\ C L & \text { Clearance } \\ P D & \text { pharmacodynamics } \\ C V & \text { coefficient of variation/relative standard deviation } \\ \log 2 F C H & \text { fold change in log2 scale }\end{array}$

\section{RESULTS - compound performance and selectivity}

LEO 134310 behaved as a full GR agonist with high affinity for GR and nanomolar anti-inflammatory potency.

\begin{tabular}{|c|c|c|c|c|}
\hline Compound & $\begin{array}{l}\text { Binding to } \\
\text { human GR } \\
\text { (N=8-17), } \\
\text { IC }_{50}(\mathrm{nM})\end{array}$ & $\begin{array}{l}\text { Inhibition of } \\
\text { human TNF- } \alpha \\
\text { (N=10-17), } \\
\text { IC } \text { C }_{50}(\mathrm{nM})\end{array}$ & $\begin{array}{l}\text { Inhibition of } \\
\text { mouse TNF- } \alpha \\
(\mathrm{N}=3), \\
\mathrm{IC}_{50}(\mathrm{nM})\end{array}$ & $\begin{array}{l}\text { Inhibition of } \\
\text { Pig TNF-a } \\
\text { (N=4-5), } \\
\text { IC }_{50}(\mathrm{nM})\end{array}$ \\
\hline LEO 134310 & 14 & 2.2 & 0.58 & 3.2 \\
\hline LEO 134998 & 150 & 260 & 35 & 210 \\
\hline CP & 4.8 & 0.52 & 0.15 & 0.38 \\
\hline BMV & 5.7 & 3.2 & 0.18 & 1.2 \\
\hline
\end{tabular}

LEO 134310 was selective for the GR and did not interact with the MR, a receptor which has been associated with induction of skin atrophy.

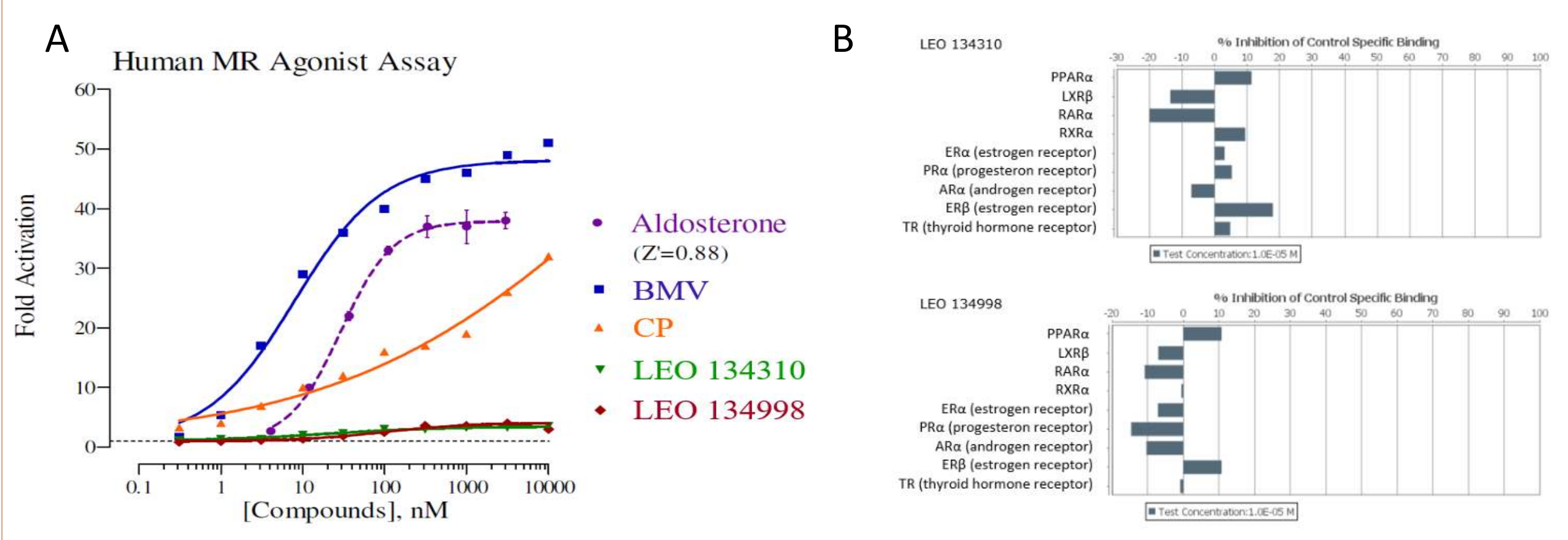

A) Human MR Agonist Assay, B) Inhibition of specific nuclear hormone receptor binding for LEO 134310 and LEO 134998 to nine nuclear hormone receptors. No significant interaction with any BMV that activated the MR.

\section{Pharmacological effects and clearance in vivo}

In a TPA-induced dermatitis mouse model LEO 134310 resolved inflammation with similar efficacy as BMV. No systemic adverse events were seen, in contrast to $\mathrm{CP}$ and $\mathrm{BMV}$ after topical treatment.

\begin{tabular}{|c|c|c|c|c|}
\hline Compound & $\begin{array}{c}\operatorname{Emax} \\
(\%)\end{array}$ & $\begin{array}{l}\operatorname{Ear~ID~}_{50} \\
(\mathrm{nmol})\end{array}$ & $\begin{array}{c}\text { Spleen ID } \\
\text { (nmol) }\end{array}$ & $\begin{array}{c}\text { Safety ratio } \\
\left(\text { Spleen } I_{50} / \text { Ear } I_{50}\right.\end{array}$ \\
\hline LEO 134310 & 62 & 3.0 & 4100 & 1366 \\
\hline CP & 87 & 0.06 & 2.1 & 35 \\
\hline BMV & 62 & $2.6^{*}$ & $69^{*}$ & $26^{*}$ \\
\hline
\end{tabular}

Clearance of LEO 134310 in man was predicted to be $>200 \mathrm{~mL} / \mathrm{min} / \mathrm{kg}$, corresponding to $>10$-fold of the liver blood flow in man.

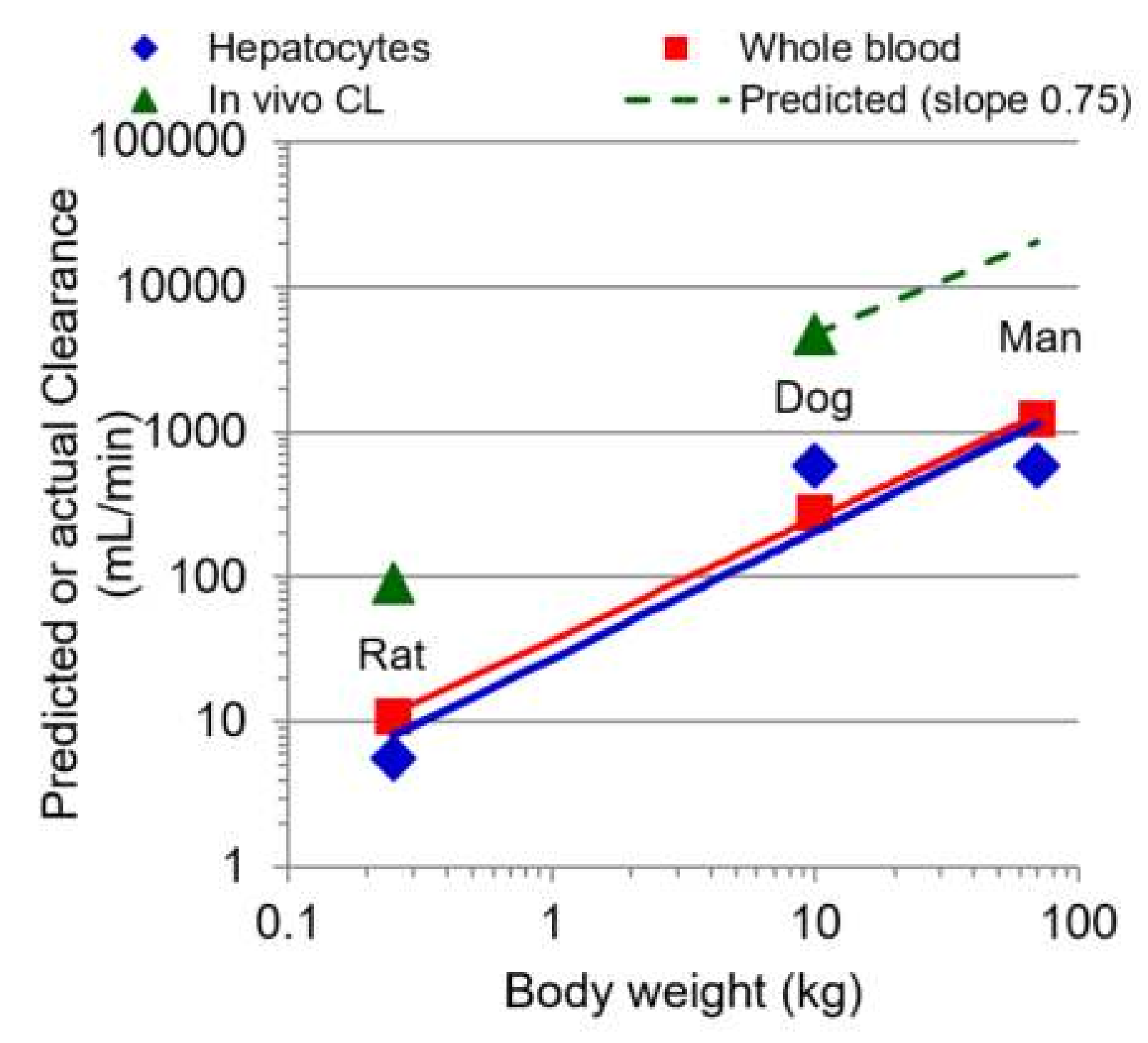

Allometric scaling of LEO 134310 from rat and dog Clearance data.

\section{CONCLUSION}

LEO 134310 shows an improved safety profile in preclinical studies compared to traditional corticosteroids and may potentially offer an improved topical treatment solution for patients with atopic dermatitis and psoriasis.

\section{Lack of atrophogenic effect in minipigs}

Minimal skin atrophy after 4-week application to minipigs was seen after treatment with LEO 134310, compared to treatment with $\mathrm{CP}$ and $\mathrm{BMV}$.

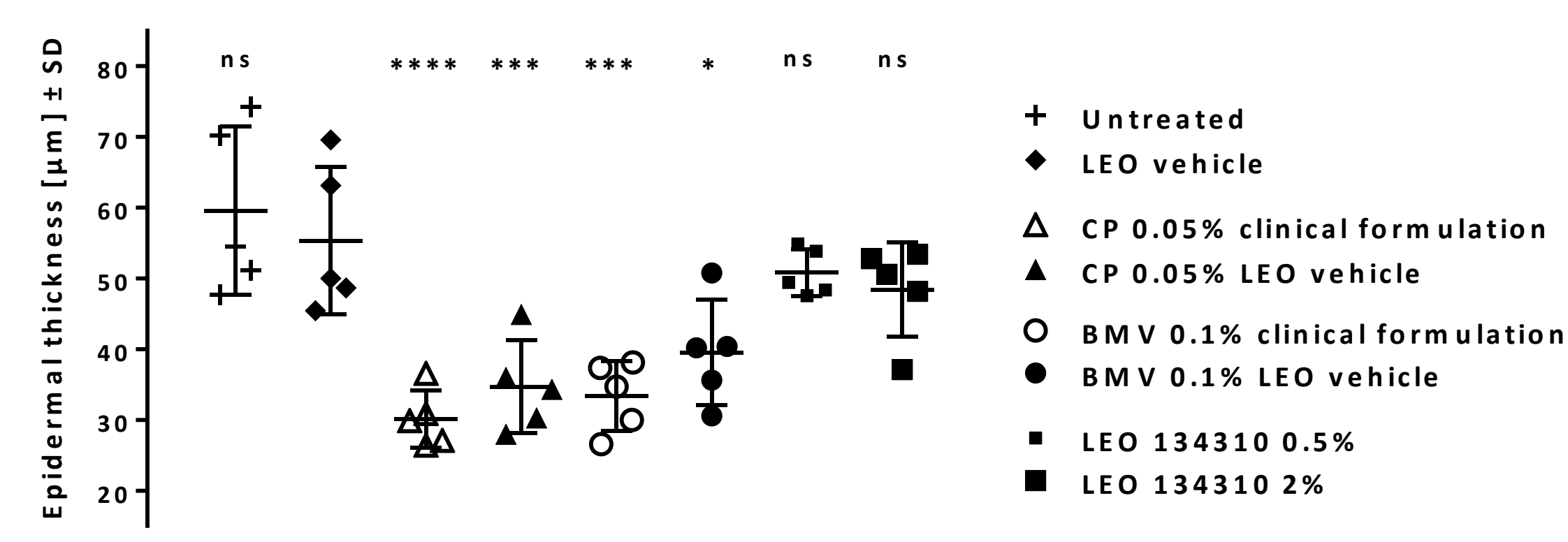

Epidermal thickness in skin biopsies from mini-pigs after 4 weeks treatment.

*: p<0.05; ***: $p<0.001 \cdot * * * * ; \quad p<0.0001$; ns: not significant. Error bars

EO 134310 had similar levels of target engagement as BMV but less than CP.

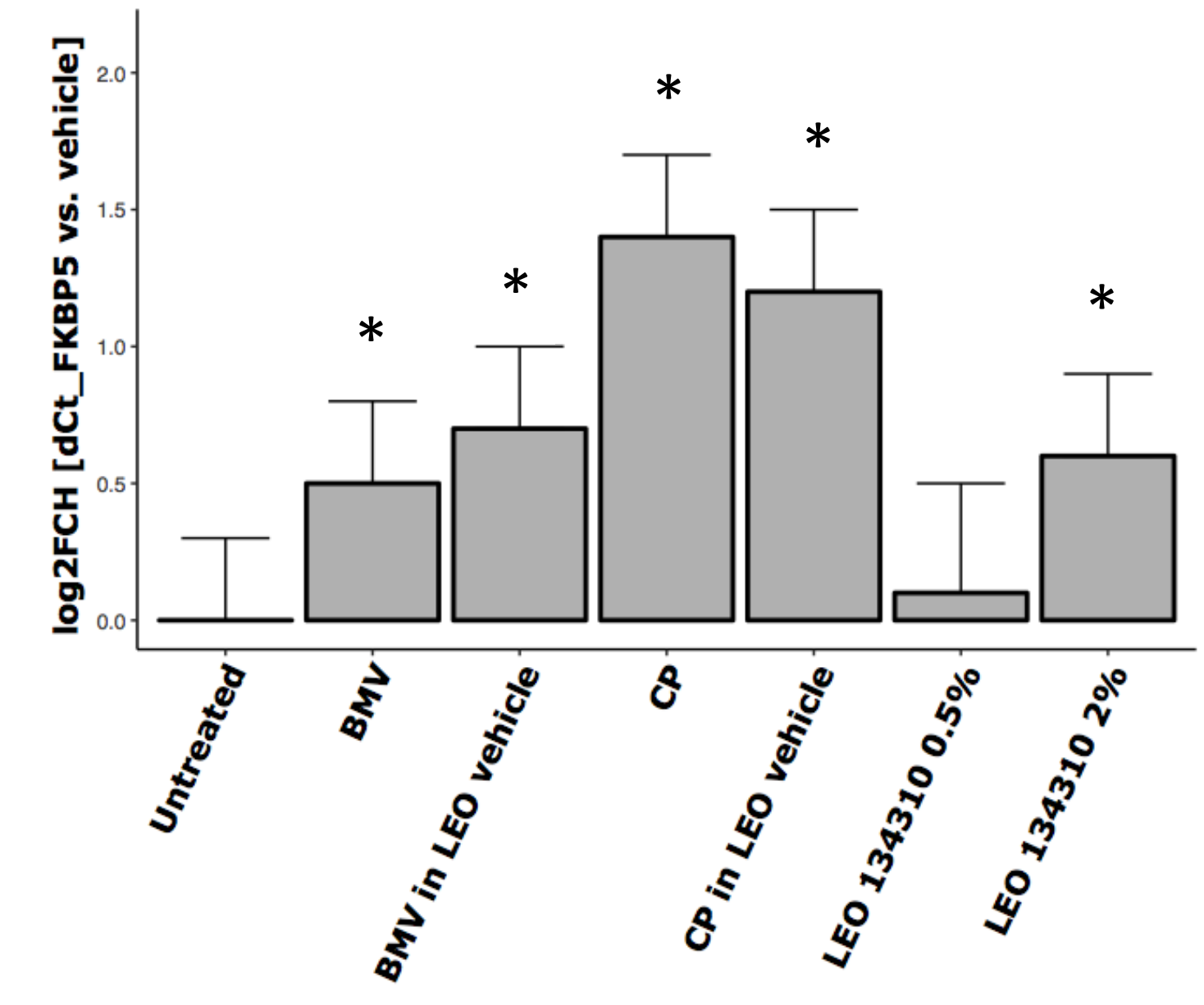

GR target engagement using the PD marker FKBP5 measured by qRT-PCR in skin biopsies from mini-pigs treated with GR agonists for 4 weeks.

( .

\section{Pharmacological activity in skin explants}

Topical treatment with LEO 134310 in a human skin explant model resulted in full agonism, measured by GR target engagement, albeit at higher dosage strength than required for BMV and CP.

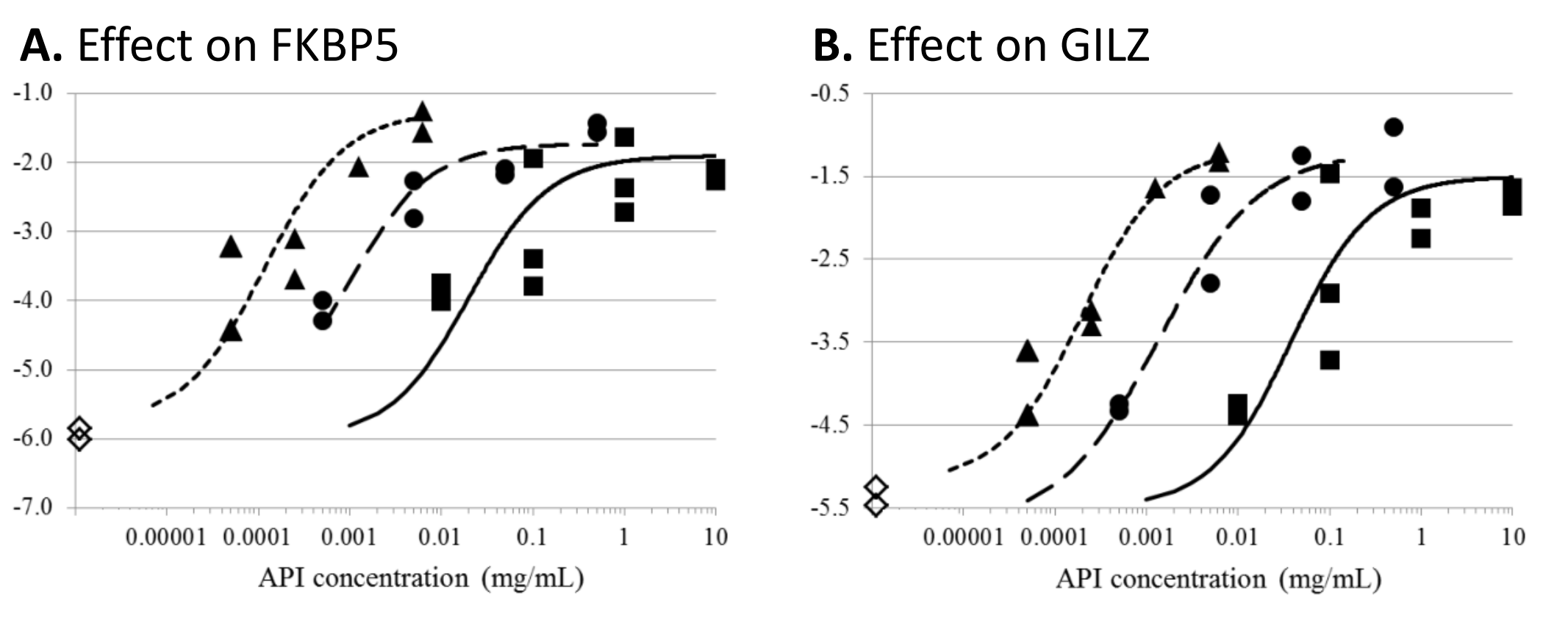

Response of GR PD markers FKBP5 and GILZ in human skin explants at 24h after dose. $\triangle \mathrm{CP} ; \bullet \mathrm{BMV}$; LEO 134310. Open symbols: untreated or vehicle treated controls. Lines represent best fits to a
(one symbol represents one explant).

Comparison of GR agonist strength on PD markers

\begin{tabular}{|c|c|c|c|c|c|c|}
\hline \multirow{2}{*}{$\begin{array}{l}\text { Compound } \\
\text { LEO } 134310\end{array}$} & \multirow{2}{*}{$\begin{array}{c}\begin{array}{c}\text { FKBP5 ED } \\
(\mathrm{mg} / \mathrm{mL})\end{array} \\
0.11(87 \%)\end{array}$} & \multicolumn{2}{|c|}{$\begin{array}{l}\text { Relative (fold) } \\
\text { to } \mathrm{CP} \text { to } \mathrm{BMV}\end{array}$} & \multirow{2}{*}{$\begin{array}{c}\begin{array}{c}\mathrm{GILZ} \mathrm{ED}_{50} \\
(\mathrm{mg} / \mathrm{mL})\end{array} \\
0.066(130 \%)\end{array}$} & \multicolumn{2}{|c|}{$\begin{array}{l}\text { Relative (fold) } \\
\text { to } \mathrm{CP} \text { to } \mathrm{BMV}\end{array}$} \\
\hline & & 360 & 31 & & 120 & 21 \\
\hline CP & $\begin{array}{c}0.00031 \\
(40 \%)\end{array}$ & & & $\begin{array}{c}0.00057 \\
(37 \%)\end{array}$ & & \\
\hline BMV & $\begin{array}{l}0.0037 \\
(100 \%)\end{array}$ & 12 & & $0.0032(80 \%)$ & 5.6 & - \\
\hline
\end{tabular}

$\mathrm{ED}_{50}$ values $(\mathrm{CV})$ calculated from curve fits were used to calculate relative strengths of LEO 134310, CP and BMV. Statistical significance was determined by one-way ANOVA analysis. 